\title{
An Albino Mutant of Blastocladiella emersonii: Comparative Studies of Zoospore Behaviour and Fine Structure
}

\author{
By D. S. SHAW* AND E. C. CANTINO \\ Department of Botany and Plant Pathology, Michigan \\ State University, East Lansing, Michigan 48823, U.S.A.
}

(Accepted for publication I6 September 1969)

\begin{abstract}
SUMMARY
A stable, ultraviolet-induced, albino mutant of Blastocladiella emersonii Cantino and Hyatt is described. It differs from wild type in: (a), capacity to form brown resistant sporangia (RS), both as 2 nd and 3 rd generation RS in clones derived from Ist generation ordinary colourless (OC) plants, and as Ist generation RS produced directly in response to exogenous bicarbonate; (b) the inhibition of growth by low concentrations of bicarbonate; $(c)$ the longer generation time, stemming from a combination of decreased growth rate and delay in spore release until terminal sporangia have become unusually large; $(d)$ the increased incapacity to discharge in situ on solid media with increasing temperatures above $23^{\circ} ;(e)$, reduced motility of zoospores and increased tendency to become amoeboid and encyst prematurely; $(f)$, certain changes in the fine structure and organization of mitochondria and their associated lipid sacs, $\gamma$ particles and the double membranes that surround nuclear caps and nuclei of spores chilled to low temperatures.
\end{abstract}

\section{INTRODUCTION}

Reports of mutations and genetic analysis of the aquatic Phycomycetes are rare [Emerson \& Wilson (1954), Emerson (1950)]. Although some aquatic Phycomycetes are sensitive to radiation (Deering, 1968) stable mutations in aquatic Phycomycetes have been observed infrequently. Among the Chytridiomycetes, Allomyces macrogynus displays clearly circumscribed haploid and diploid phases; yet, even in such haploid thalli, where recessive mutations should not be masked, mutations have apparently been rare. Thus, while female-less (Stumm, 1958) and albino (Foley, 1958) variants have been produced, as well as mutants with decreased capacity to form RS (De Long, 1965), the latter (according to De Long) was but the third example in the literature of a well established single-gene mutation in Allomyces, and the first example of a singlegene lesion displayed by the diploid sporophyte. In biflagellate fungi (often assumed to be haploid, although morphological and cytological evidence for Achlya, Dictyuchus, Pythium and Phytophthora; Mullins \& Raper, 1965; Sansome, 1965, now suggests they may be diploid) the situation is much the same.

The biochemistry of RS morphogenesis and the changes in fine structure associated with zoosporogenesis in Blastocladiella emersonii have been studied in some detail (Cantino \& Lovett, 1964; Lessie \& Lovett, 1968); as yet genetic studies have not been

\footnotetext{
* Present address: School of Plant Biology, University College of North Wales, Bangor.
} 
possible. Because the fungus reproduces asexually by motile spores released from colourless thin-walled OC plants, it has been tempting to think that (as in some species of its close relative, Allomyces) meiosis might be taking place in RS plants when sporogenesis occurs. However, RS spores look and behave much like OC spores (Cantino \& Hyatt, I953a; Cantino, I969b) and true sexual fusions between any kinds of spores have never been observed. Spores from OC and RS plants can give rise to a few $O$ (orange) plants that release orange swarmers in which fewer cytoplasmic $\gamma$ particles occur (Cantino \& Horenstein, 1956). Most orange swarmers are nonviable, and none has ever been seen to exhibit conventional sexual activity (Cantino \& Hyatt, 1953a). During some 20 years of almost daily culturing of $B$. emersonii, variant clones displaying altered colours and/or gross texture and morphology have appeared spontaneously only about six times (E. C. Cantino, unpublished data); from only two of these were isolates obtained that could be propagated as stable mutant strains for a number of years; both of these were orange phenotypes. Possible relationships among the orange cell types produced by the Blastocladiales are considered more fully elsewhere (Cantino, 1966).

In the present study our original aim was to produce nuclear markers with which we could begin a genetic analysis of Blastocladiella emersonii, define its ploidy, detect and establish the nature of recombination if it occurred and eventually study the bicarbonate trigger mechanism for RS differentiation with incompetent mutants. Repeated attempts were made to produce and isolate such markers, yet only one stable variant (strain 9) incompetent to form RS was ever produced. The following report concerns differences between strain 9 and its wild type parent.

\section{METHODS}

Nature of the wild-type stock culture

Following the first studies (Cantino, 195I) and subsequent description (Cantino \& Hyatt, I953a) of Blastocladiella emersonii as a new species, day-to-day working cultures of the fungus have generally been maintained by successive cultivation using spores derived from clones of OC plants. But to ensure stability of the strain, RS spores from aged RS clones were used every few months to initiate new stocks of OC plants. As far as we know, cultures maintained in this way for the past I8 years do not differ from the original isolate. We refer to such strains as 'wild type'.

For some 4 years we have also kept one strain going exclusively via OC plants and OC spores. This strain now differs in some respects from wild type. On PYG agar (Difco Laboratories, Detroit, Mich., U.S.A.) its clones do not become pigmented as deeply brown as do those of wild type because fewer of the thalli develop into brown pitted RS types; furthermore, among those that do, many do not lay down the usual amount of pigment in the thickened wall. Thus, altered capacity for morphogenesis and melanogenesis may stem in part from a decreased capacity to respond to bicarbonate. Also, when OC spores are inoculated to PYG agar containing $\mathrm{NaHCO}_{3}$ at concentrations which induce RS in the wild type, not all the growing thalli respond to form individual RS plants. Instead, variable numbers of plants arise that possess the usual distinctive shape of an RS thallus grown under these conditions but do not discharge spores in situ as would an OC cell; yet these plants bear larger thinner-walled sporangia than their RS counterparts in the populations. In fact, they strikingly 
resemble the RS-like plants induced many years ago (Cantino, I95I) with exogenous pyrophosphate. The proportion of our 'pseudo RS' types (cf. Domnas, 1968), in a population of bicarbonate-induced RS cells can range from nil to very high levels depending upon a variety of factors among them are population density and media autoclaving time. The differences between this variant and its parent have not yet been fully analysed. To distinguish between the two, we have designated the variant as 'wild type var. I'. In the present report wild type var. I was the only wild type used.

\section{Production of zoospore suspensions}

About $5 \times 10^{3}$ zoospores were spread out on freshly poured PYG agar in $150 \mathrm{~mm}$. diam. plastic Petri plates at about 32 spores $/ \mathrm{cm}^{2}$ and incubated in the dark at $20^{\circ}$ (wild type var. I) or $24^{\circ}$ (mutant strain 9). After about $24 \mathrm{hr}, 75$ to $90 \%$ of the OC cells had discharged spores into the residual surface film of fluid remaining from the original inoculum. Populations of spores produced under these conditions consisted predominantly if not exclusively of elongate amoeboid swarmers. Plates were then flooded with $9 \mathrm{ml}$. water; after $5 \mathrm{~min}$., the resulting spore suspension $\left(10^{6}\right.$ to $5 \times 10^{6}$ spores $/ \mathrm{ml}$.) was removed, placed in an ice bath, and samples fixed immediately for electron microscopy and/or measured in a model B Coulter counter. When used as inocula for synchronized liquid cultures, spores were kept at $\mathrm{I}$ to $2^{\circ}$ for $2 \mathrm{hr}$ to improve synchrony (Cantino, Truesdell \& Shaw, 1968).

\section{Synchronized single generation cultures}

Spores pre-chilled for $2 \mathrm{hr}$ were inoculated into water-jacketed, $500 \mathrm{ml}$. spinner flasks (Bellco Glass Inc., Vineland, New Jersey) containing $200 \mathrm{ml}$. PYG + phosphate + citrate (PYG-PC; Cantino \& Goldstein, 1967) at $24^{\circ}$. Population densities were $10^{5}$ and $5 \times 10^{5}$ spores $/ \mathrm{ml}$. in various experiments; aeration, at $21 . / \mathrm{min}$., and magnetic stirring were started $2 \mathrm{hr}$ after inoculation. Thalli were induced to differentiate sporangia and discharge spores by replacing spent media with the ' $\mathrm{I} / 2 \mathrm{DS}$ ' solution of inorganic salts of Murphy \& Lovett (I966).

\section{Ultraviolet irradiation}

About $5 \times 10^{5}$ wild type var. I spores were spread out on about $57 \mathrm{~cm}^{2}$ surface of wettable cellulose film placed on top of PYG agar, incubated until most thalli had reached the 8-nucleate stage (c. $7 \mathrm{hr})$, irradiated with a General Electric no. G 3028 $30 \mathrm{~W}$ germicidal lamp for $\mathrm{I} 60 \mathrm{sec}$., and then incubated in the dark for an additional I4 $\mathrm{hr}$. The film with organisms attached was then transferred to Io $\mathrm{ml}$. of $\frac{1}{2}$ DS solution; zoospores released therefrom were collected after $4 \mathrm{hr}$ and served as the source of mutants. Unless zoospore formation was induced this way, maturation of $\mathrm{OC}$ organisms and zoospore discharge was extremely asynchronous as compared with non-irradiated controls.

\section{Electron Microscopy}

Spore suspensions were derived either from plate cultures or from OC plants (about $10^{5} / \mathrm{ml}$.) grown in spinner flasks as described above; the spent media in flask cultures were replaced by $\frac{1}{2}$ DS solution after $18 \mathrm{hr}$, and samples removed and fixed at various times before and during spore cleavage. Spore suspensions were centrifuged at $\mathrm{I} 800 \mathrm{~g}$ for I to $2 \mathrm{~min}$; t the loose pellet thus produced was fixed as follows.

Fixation. Stock solutions of glutaraldehyde $(50 \%), \mathrm{OsO}_{4}(2 \%)$ and $\mathrm{KMnO}_{4}(4 \%)$ 
were diluted with $\mathrm{I} \cdot 8 \times 10^{-2} \mathrm{M}-\mathrm{Na}$ veronal $+\mathrm{Na}$ acetate buffer $(\mathrm{pH} 7 \cdot 8)$ to yield $2 \%$, I $\%$ and $2 \%$ solutions, respectively (Lessie \& Lovett, 1968). Spores fixed I hr in glutaraldehyde were postfixed $\mathrm{I} \mathrm{hr}$ in either $\mathrm{OsO}_{4}$ or $\mathrm{KMnO}_{4}$; the latter was also used alone $(2 \mathrm{hr}$ ). Equal volumes, usually $3 \mathrm{ml}$., of spore suspension and cold fixative were mixed, loosely pelleted immediately at low speeds, suspended in fresh cold fixative and kept on ice for the desired times.

Dehydration. Pellets were dehydrated successively in 25, 50, 75 and $95 \%$ ethanol in water, containing $\mathrm{I} \% \mathrm{MgCl}_{2}$ for $\mathrm{Io} \mathrm{min}$. each, followed by a final dehydration in absolute ethanol.

Embedding. Pellets were treated successively with ethanol solutions containing increasing proportions $(3+\mathrm{I}, \mathrm{I}+\mathrm{I}, \mathrm{I}+3)$ of propylene oxide for $\mathrm{I} 0 \mathrm{~min}$. each, and with pure propylene oxide for 30 min., transferred to propylene oxide + Epon $812(I+I)$ overnight and finally embedded in gelatin capsules with Epon 812 $(7+3)$.

Sectioning. Sections were cut with a Porter-Blum MT-2 ultramicrotome with a diamond knife, mounted on 400-mesh copper grids and examined with a Phillips $100 \mathrm{~B}$ electron microscope.

\section{RESULTS}

\section{Isolations and characterization of the albino mutant}

Spores from irradiated OC organisms were dispersed on 40 plates of PYG agar, half of them with about $\mathrm{I} \cdot 3$ spores $/ \mathrm{cm}^{2}$ and the other half about $2.6 \mathrm{spores} / \mathrm{cm}^{2}$. Viability, in terms of the capacity to form first generation OC plants, was roughly comparable to that of non-irradiated spores. After 5 days almost all clones derived from irradiated spores, like those on control plates, contained many brown RS cells. However, Io white clones were found in which RS were absent or only rarely detected. We determined, therefore, whether the progeny from such clones were competent to differentiate RS organisms when exogenous $\mathrm{NaHCO}_{3}$ was provided. Random samples of zoospores from each clone were transferred at about 0.9 to $\mathrm{I} .8 \mathrm{spores} / \mathrm{cm}^{2}$ to PYG media containing bicarbonate at several concentrations between zero and $5 \times 1 \mathrm{IO}^{-2} \mathrm{M}$. After 3 days populations were scored for plants that released spores to form clones and for brown RS among those that did not discharge. Figure I A shows the cloning competence of progeny derived from nine variants and from three wild type var. I controls. Although all isolates differed from the wild type in their response to $\mathrm{NaHCO}_{3}$, strain 9 was outstanding in that $(a)$, no detectable melanin was produced by plants grown on any of the media; and $(b)$, its spores displayed very low viability on PYG containing $5 \times 10^{-3} \mathrm{M}-\mathrm{NaHCO}_{3}$, while those that did germinate did not develop into mature cells.

Additional tests with successive generations derived from most of these strains showed that capacity for cloning on bicarbonate media and for melanin production was variable, whereas strain 9-after partially regaining some cloning competence during successive sub-culturing-became particularly stable in both of these respects. The response of progeny derived from three such clones of the stabilized strain 9 is compared in Fig. I B with that from three clones of wild type. Cloning by strain 9 was completely inhibited by $5 \times 10^{-3} \mathrm{M}-\mathrm{NaHCO}_{3}$, a concentration whereon most wild-type thalli developed into $\mathrm{OC}$ plants which then discharged spores and formed clones. Instead, strain 9 produced uniformly large colourless cells without thickened walls which neither discharged nor developed further in any obvious way. Strain 9 did form 
clones on lower concentrations of $\mathrm{NaHCO}_{3}$, but such colonies did not contain the pitted brown RS plants which typified wild-type clones. The colonies did produce regularly, but at low frequency, thin-walled yellow-orange cells which resembled the O-cells of Cantino \& Hyatt (1953a). Periodic tests have shown that lack of cloning competence on bicarbonate media has remained a stable feature of strain 9 for 3 years.

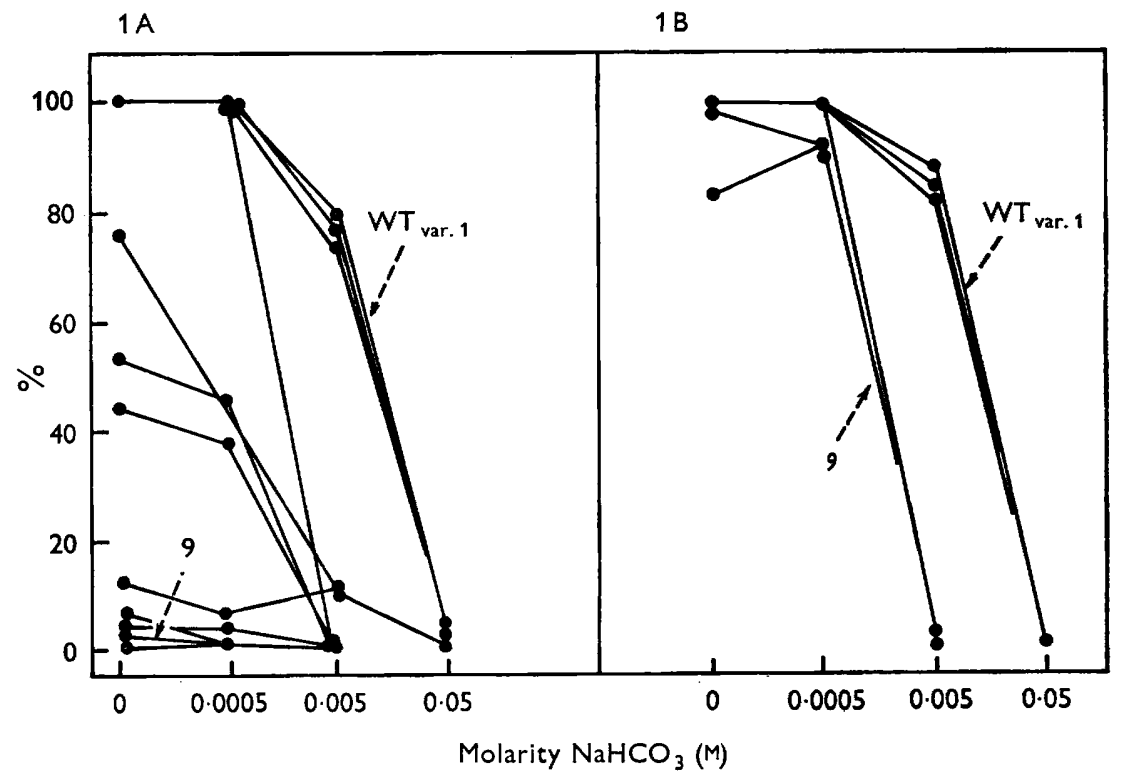

Fig. I A. Cloning competence of populations of individual plants (\% discharging to yield clones) derived from zoospores of three wild type var. I and nine mutant albino strains (including strain 9) on PYG-agar media containing up to $5 \times 10^{-2} \mathrm{M}-\mathrm{NaHCO}_{3}$.

Fig. I B. Cloning competence of three clones from subsequent progeny (several generations later) of albino strain 9, and three clones of wild type var. I ; conditions as for Fig. I A. (Mechanism by which cloning competence was regained during subculturing is not understood.)

Individual plants of strain 9 on PYG agar also matured less rapidly than those of wild type var. I. Rates at which populations of the wild type and mutant plants discharged spores in situ on PYG agar were compared at temperatures between 17 and $32^{\circ}$ (Fig. 2). At all temperatures the interval between the time a spore was placed upon the agar and the time the $\mathrm{OC}$ cell derived from it released its spores onto the medium (the generation time) was longer for the mutant. Furthermore, with temperatures above $23^{\circ}$, the populations of strain 9 plants discharged their spores with decreased synchrony (note decreasing slopes in Fig. 2, top); also, more and more of them lost the capacity to produce and/or discharge spores. The temperature which yielded the highest proportion of normally discharging cells in the shortest time was $26^{\circ}$ for the wild type and $23^{\circ}$ for strain 9 .

Synchronized single-generation liquid cultures of the mutant and wild type were also started with spores $\left(\mathrm{I} \cdot 6 \times 10^{4} / \mathrm{ml}\right.$.) in medium PYG-PC at $24^{\circ}$ agitated with a stream of air; plant sizes were recorded during development (Fig. 3). The rate of increase in cell volume was higher for the wild type; however, the mutant thalli continued growing at their slower rate for a longer time, and achieved a larger size before they formed papillae and differentiated spores. 


\section{Comparative behaviour of zoospores}

Mutant cells were grown on PYG agar (about 6.5 plants $/ \mathrm{cm}^{2}$ ) until a few had begun to discharge spores and were then flooded with water. As zoospores emerged from sporangia, they were seen to differ from the wild type in their behaviour. They lacked the intense activity of wild-type spores under similar conditions; they swam sluggishly for brief periods and then settled quickly on the agar surface, where they exhibited amoeboid movements and then either encysted or swam slowly again.

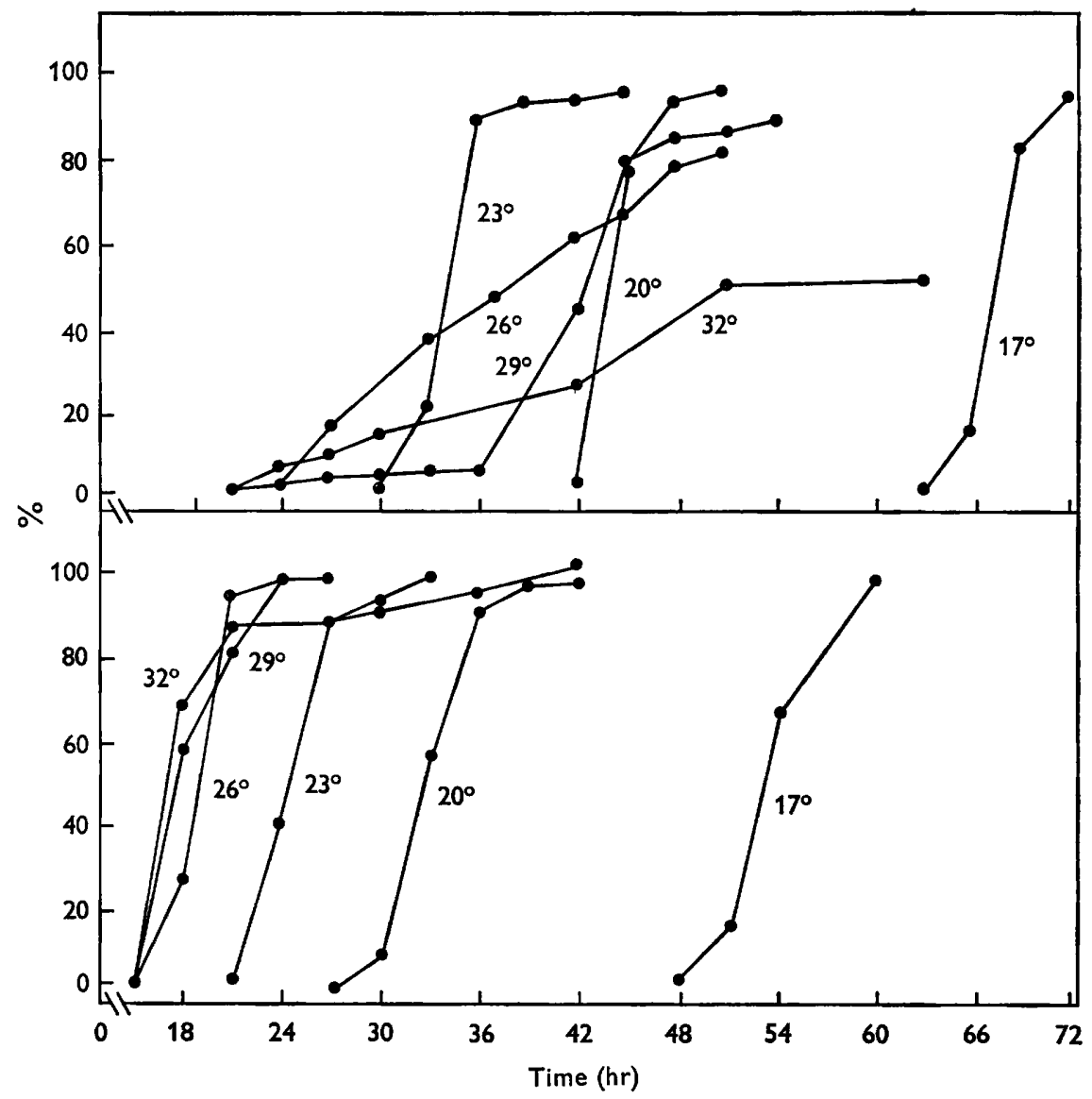

Fig. 2. Rate of maturation of populations of individual plants (as $\%$ discharging spores $v s$. time) of wild type var. I (bottom) and albino mutant strain 9 (top) on PYG-agar at different temperatures.

Fine structure of wild-type and mutant zoospores

Actively swimming wild-type zoospores of Blastocladiella emersonii are subglobose to ellipsoid. Numerous aspects of the fine structure of such spores have already been described (Cantino, Lovett, Leak \& Lythgoe, 1963; Fuller, 1966; Lessie \& Lovett, 1968). When spores were first released from dense populations of OC plants into a surface film of fluid on solid media, they were irregularly elongated rather than 
smoothly ovoid and crawling amoeboids rather than active swimmers. With the harvesting method used here, we examined the structure of these amoeboid spores, compared it with that of similar spores stored over ice for $2 \mathrm{hr}$, and contrasted this with known facts about swimming spores (cf. Cantino et al. 1968).

The amoeboid and chilled zoospores of wild type var. I. The fine structure of amoeboid spores differed little from previously published pictures. They displayed more or less elongate shapes with pseudopodial protrusions. The single nucleus was bounded

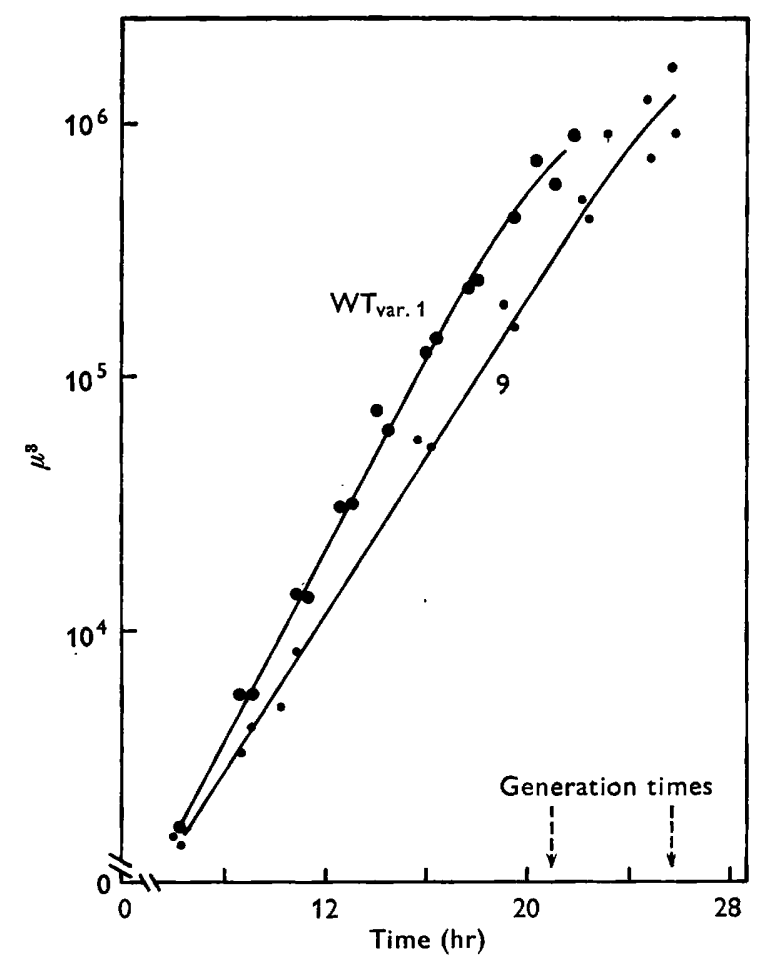

Fig. 3. Rate of increase in average cell volume of wild type var. I and albino mutant strain 9 inoculated with $1 \cdot 6 \times 10^{4}$ spores $/ \mathrm{ml}$, and grown in aerated liquid medium PYG-PC at $24^{\circ}$. (Representative results from one experiment.)

by a partially porous membrane and was almost completely surrounded on its posterior side by ribosomal particles enclosed within a continuous double membrane that delimited the spore's nuclear cap, now chemically characterized (Lovett, 1963).

An unexpected feature of wild-type amoeboid spores was the persistent occurrence of one to several satellite ribosome packages (Cantino, 1969a) apparently identical in texture and osmiophilic properties with the particles in the nuclear cap. These ribosome packages were delimited by their own continuous double membranes, and were situated in the cytoplasm outside the nuclear cap, and sometimes even in locules almost completely enclosed by the mitochondrion. The membrane around these ribosome packages is now known to be connected solely to the outer unit membrane of the nuclear cap (Cantino \& Mack, 1969).

The spore's single mitochondrion was asymmetrically disposed as usual about the nucleus at the posterior end of the spore, where it was associated with flagellar fibres 
and membrane-covered banded rootlets as in swimming spores. In view of the presently unresolved nature of the attachment between rootlets and kinetosome, it is noteworthy that one of our pictures (Pl. 4, fig. 7) of this association is very similar to one (Fig. 55) published by Lessie \& Lovett (I968) which prompted their comment that '.. in some sections two of the rootlets actually seem to be arms of a single continuous structure that passes close to (or is attached to) the basal body fibrils...' Finally while we have frequently seen sections (of both the wild type and wild type var. I) showing three mitochondrial canals, only two of them ever contained banded rootlets, the third containing only ill-defined material. We have yet to see unmistakable evidence, either among our own sections or those published by others, for the conclusion (Fuller, 1966; Reichle \& Fuller, 1967) that the zoospore of Blastocladiella emersonii possesses three banded rootlets.

The significance of the differences among the granules situated in the doublemembraned lipid sac (Cantino et al. 1963, Lessie \& Lovett, 1968; Reichle \& Fuller, 1967) along the outer edge of the mitochondrion is still uncertain. In amoeboid as in swimming spores, these granules always appeared in two forms: one, an often elongated membrane-bound organelle (possibly a continuous matrix) of even electron density; the other, situated among the former, a somewhat polyhedral body with an electron-transparent centre and an electron-opaque limiting region. Originally, these two types of bodies were simply lumped together and termed 'lipid granules' (Cantino et al. 1963); later, they were distinguished as spherical lipid granules and 'sb' granules by Lessie \& Lovett (1968), who re-interpreted earlier views (Reichle \& Fuller, 1967) of these granules.

Other structures in amoeboid spores, seen previously in vivo by phase microscopy (Cantino et al. 1968), are the large transparent vacuoles found most often in the cytoplasm at the amoeboid's anterior end. Sometimes they were so disposed as to suggest that they were in the process of breaking through to the outside. And finally, the structure of the $\gamma$ particles appeared to be normal. In contrast, the wild-type zoospore chilled for $2 \mathrm{hr}$ exhibited some marked structural changes. The cell was now globose or sub-globose (PI. I, fig. I). Its nuclear apparatus (i.e. its assemblage of nucleus, nucleolus and nuclear cap) was displaced far to one side probably due to the change in shape of the mitochondrion. The latter had become almost completely spherical but remained secured to the basal region of the flagellum by a small loop, all that remained of it on one side of the still anchored flagellum (Pl. 4, fig. 7, arrow). Simultaneously, the volume of the spore increased, and its cytoplasm became more electron transparent. The membranes of the lipid sac were frequently fragmented and lipid bodies often lay scattered in the cytoplasm. Other details about the structure and metabolic activity of such chilled wild-type spores have been reported elsewhere (Cantino, Suberkropp \& Truesdell, I969).

The amoeboid and chilled zoospores of mutant strain 9. Unchilled amoeboid spores of the mutant also contained one or more satellite ribosome packages bound by double membranes and located outside the nuclear cap. Other organelles apparently did not differ from those in unchilled wild-type amoeboid spores.

However, additional differences became apparent after mutant spores were chilled. They were generally larger than chilled wild type spores and in most the double membrane around the nuclear cap was incomplete (arrows in Pl. I, fig. 2; Pl. 2, fig. 3 and 4). Such holes-in a membrane very rarely imperfect in wild-type spores- 
almost always occurred along the sides of the nuclear cap near the normal point of continuity of its membrane with that of the nucleus; this normal joining point is illustrated in Pl. 5, fig. 9 (arrow).

The double membrane of the nuclear cap was sometimes seen (Pl. 2, fig. 4, dotted arrow) to be continuous with the membrane of the lipid sac, yet separate from the nuclear membranes. This, however, is a different kind of breach of the cap's intactness that also occurs in wild-type spores (Cantino \& Mack, I969, fig. I I; Lessie \& Lovett, 1968).

The smaller of the two gaps in the nuclear cap membrane pictured in Pl. 2, fig. 3 (dotted arrow) clearly demonstrated both the double nature of the membrane and the fact that such breaks were not due to artifacts of section preparation. Angular vacuoles were sometimes seen (Pl. I, fig. 2; Pl. 2, fig. 3) near the gaps in the nuclear caps.

In addition to their imperfect nuclear caps, chilled mutant zoospores also displayed imperfect nuclear membranes (Pl. 3, fig. 5, arrow). Such spores appeared normal in other respects. Sections of sporangia undergoing sporogenesis also revealed (Pl. 3, fig. 6, arrow) that discontinuities in nuclear membranes were detectable even before zoospores had been fully differentiated and released. Examples of the sort depicted in this figure were commonly seen in sporangia.

Chilled mutant spores had globose shapes resembling those of chilled wild-type spores; yet, their mitochondria (although they did become compacted, Pl. I, fig. 2; P1. 2,; Pl. 6, fig. II) never took on the nearly spherical shape so typical of mitochondria in chilled wild-type spores (compare Pl. 6, fig. I0, with Pl. 6, fig. II). The associated lipid sacs did not become as disrupted as those in the wild type. The $\gamma$ particles, entirely normal in unchilled mutant spores, took on seemingly distorted and sometimes unusual shapes when spores were chilled.

The banded rootlets in the mutant seemed to be normally placed in mitochondrial canals and associated with the kinetosome. Striations were seen in longitudinal sections of rootlet axes; little is known about their nature or significance. When fixed with $\mathrm{KMnO}_{4}$ alone ( $\mathrm{Pl}$. 4, fig. 7), the bands in chilled spores appeared to be of two types, one alternating with the other. An unusual view of a banded rootlet ( $\mathrm{Pl} .4$, fig. 8) -in this case, in an unchilled mutant spore stained with lead citrate and uranyl acetate-suggested that these striations were enclosed within a distinct sleeve only vaguely visible in $\mathrm{Pl} .4$, fig. 7 .

\section{DISCUSSION}

Ultraviolet irradiation of Blastocladiella emersonii led to formation of some visibly altered clones; one such phenotype, the albino strain 9, described here, differed structurally and functionally from its parental wild type var. I in that: $(a)$, the fine structure of its zoospores, particularly the membrane system delimiting the nuclear apparatus, was especially sensitive to modification by cold treatment; $(b)$, its zoospores displayed decreased motility; $(c)$, the growth rate of the thalli derived from these spores was less, and the size of plants, at generation time, greater than those from wild type strains; $(d)$, spore germination and/or subsequent growth were inhibited by concentrations of exogenous $\mathrm{NaHCO}_{3}$ that induced $\mathrm{RS}$ formation in wild type strains; $(e)$, it did not produce RS plants in response to those concentrations of exogenous $\mathrm{NaHCO}_{3}$ that did permit growth.

Deering (I968) reported some pronounced changes in the u.v. sensitivity of germ- 
lings of Blastocladiella emersonii when they were irradiated at different developmental stages, and he discussed possible reasons for these results in terms of nuclear division cycles and other factors. Apparently, no stable albino mutant such as ours arose or was established in the course of Deering's studies. However he worked with one- to four-nucleate germlings while we irradiated eight-nucleate plantlets.

\section{Table I. Comparative properties of Blastocladiella emersonii and some strains derived from it ${ }^{*}$}

Comparison of zoospore characteristics

Wild type var. I Mutant strain BEM Mutant strain 9

(vs. wild type)

\begin{tabular}{llll}
$\begin{array}{l}\text { Size (wild type = about } \\
\text { for colourless spores) } \\
\text { Motility }\end{array}$ & Similar & Similar & Similar \\
Viability & Similar ${ }^{\dagger}$ & $\begin{array}{l}\text { Altered } \\
\text { ('zig-zag') } \\
\text { Greatly } \\
\text { decreased } \\
\text { (to about } \mathrm{I} \%)\end{array}$ & $\begin{array}{c}\text { Altered } \\
\text { (sluggish) } \\
\text { Somewhat } \\
\text { decreased }\end{array}$ \\
$\begin{array}{l}\gamma \text { particles/cell (wild type }=\text { about } \\
\text { I3 for colourless spores) } \\
\text { Changes in fine structure? }\end{array}$ & $?$ & 8 & $?$ \\
\hline
\end{tabular}

Nature of populations of first generation individual thin walled plants derived from zoospores

Generation time (as \% of wild-type gen. time)

Colour at maturity (vs. wild type $=$ $99 \%$ colourless, $1 \%$ orange)

\begin{tabular}{|c|c|c|}
\hline About $100 \%$ & About $120 \%$ & About $120 \%$ \\
\hline Similar & $100 \%$ orange & $\begin{array}{l}\% \text { orange erratic, } \\
\text { variable } ; \text { mostly } \\
\text { colourless }\end{array}$ \\
\hline No & Yes (total loss) & Yes (total loss) \\
\hline Yes (reduced) & Yes (total loss) & Yes (total loss) \\
\hline Yes (reduced) & Yes (total loss) & Yes (total loss) \\
\hline$?$ & Yes & $?$ \\
\hline
\end{tabular}

Change in capacity to grow like wild type in $10^{-2} \mathrm{M}$ to $5 \times 10^{-3} \mathrm{M}$ bicarbonate?

Change in capacity to form RS plants directly in response to bicarbonate like wild type?

Change in capacity to form clones bearing RS plants on non-bicarbonate media like wild type?

Changes in enzyme activity characteristic of wild type?

* For references to the original papers upon which this summary is based, see Cantino, 1966.

$\ddagger$ It is noteworthy that in Blastocladiella britannica (Horenstein \& Cantino, I96I), an albino variant (strain TW) incapable of producing RS plants in clones was also characterized by: $(a)$ lack of capacity to produce RS in response to bicarbonate; $(b)$, inability to grow at concentrations of bicarbonate between $\mathrm{IO}^{-2} \mathrm{M}$ and $5 \times \mathrm{IO}^{-3} \mathrm{M} ;(c)$, an extended generation time as high as three times that of the parental type.

$\dagger$ Soll, Bromberg \& Sonneborn (1969) reported that the zoospores of wild type var. I behave identically with the wild type in their germination assays.

In any case, the altered properties (Table I) of our albino strain 9 are reminiscent of the features displayed previously by spontaneous orange mutants (e.g. strain BEM; Cantino \& Hyatt, I953b) of Blastocladiella emersonii. In view of the number and kinds of changes involved, perhaps albino strain 9 also arose (as suggested earlier for orange mutants; Cantino \& Lovett, 1964) by mutation in a single pleomorphic nuclear 
gene. Without more direct evidence, however, the changes which gave these two new phenotypes remain obscure.

Aside from questions about the origin of Blastocladiella mutants, there emerged some interesting details about zoospore fine structure, namely, the cold-induced breaks in the membrane around the nuclear apparatus. The enclosure of a zoospore's ribosomes in a membranous structure such as a nuclear cap apparently is not vital for all uniflagellate aquatic fungi; the motile spores of some Chytridiomycetes, for example, bear naked aggregates of ribosome-like particles either randomly distributed or localized around or near their nuclei, while others may enclose them only partially within loose networks of imperfect double membranes (Fuller, 1966; Chambers, Markus \& Willoughby, 1967). And in the spores of Monoblepharella (Fuller \& Reichle, I968), ribosome-like bodies are found in two major areas: scattered at the cell's posterior, where they are not delimited by membranes; and closely packed around the nucleus, where they are partially delimited by flattened cisternae but otherwise in contact with cytoplasm. At the other extreme is the situation found in Blastocladiella emersonii and its derivatives: the regular appearance in unchilled zoospores of a doublemembraned nuclear cap that encloses essentially all its ribosomes, and (at least in some spores) additional small packets of ribosome-like particles, also delimited by double membranes but situated in the cytoplasm. Such satellite ribosome packages had not been seen (Cantino et al. 1963) - or seen only very rarely (Reichle \& Fuller, 1967; Lovett, personal communication) - by previous workers in spores from wild-type stocks of $B$. emersonii, and it had not been determined whether they were connected to the cap or enclosed by separate membranes of their own. It is now known (Cantino \& Mack, I969) that they connect solely to the outer unit membrane of the nuclear cap's double membrane, and that they can be released as separate entities. The high frequency with which they have been found in the present study and in later work (Cantino, I969 $b$; Cantino \& Mack, 1969) suggests that they may be especially prevalent in, if not a special feature of, amoeboid spores as compared to swimming spores. At present the functional significance of these satellite ribosome packages is unknown.

With the nuclear cap itself, cold shock induces it to fracture in the albino mutant but not in the wild type. Rupture of this cap and release of its ribosomes to the cytoplasm is apparently an obligatory event associated with germination of wild-type zoospores (Lovett, 1968). It is conceivable, therefore, that an increase in germinability (or improvement in the synchrony of germination) of mutant spores might result from a premature induction of such a membrane lesion by cold shock; unpublished data do suggest that the percentage germination for a population of cold-shocked mutant spores is increased. However, the potential significance of this correlation is weakened by the fact that cold shock also affects the behaviour of wild-type spores (Cantino et al. 1968; Cantino et al. 1969), yet their nuclear caps remain intact at these lowered temperatures.

In contrast to these changes in the mutant's nuclear cap, the shape of the single mitochondrion in the albino's spore is much less affected by cold shock than is the wild type's. It would seem as if the membranes around these two types of organelles respond quite differently to a decrease in temperature, but in reciprocal fashion. If lowered temperatures should cause physical modification of the lipid structures in the spore membranes so as to change their permeability, as suggested by Schramm, 
Eisenkraft \& Barkai (1967) for other biological systems, perhaps cold-induction of different degrees of 'leakiness' among the organelles in wild-type spores and mutant spores is involved in the phenomenon. Perhaps microtubules might also be involved, considering (a), reports that in Blastocladiella emersonii they extend upward (as an array of nine sets of three) from the kinetosome region to ensheath the nuclear cap (Lessie \& Lovett, 1968; Fuller \& Calhoun, I968), and (b), that low temperatures cause microtubules to disappear in other organisms (Roth, 1967; Tilney \& Porter, 1967). At the moment, however, we have no direct evidence to support these possibilities. Although work has begun (Cantino et al. 1969) to analyse in physiological terms the effect of cold shock upon wild-type spores, this has not been done with the albino mutant.

The work reported herein was supported by a NATO Post-doctoral Fellowship to D.S.S., and by research grants from the National Institutes of Health and the National Science Foundations to E.C.C.

\section{REFERENCES}

Cantrno, E. C. (195I ). Metabolism and morphogenesis in a new Blastocladiella. Antonie van Leeuwenhoek. J. Microbiol. Serol. 17, 325.

Cantino, E. C. (1966). Morphogenesis in aquatic fungi. In The Fungi, vol. 2, p. 283. Ed. by G. C. Ainsworth and A. S. Sussman. New York and London: Academic Press.

Cantino, E. C. (1969a). Physiological age and germinability among resistant sporangia of Blastocladiella emersonii. Trans. Br. mycol. Soc. 59, ro6o.

Cantino, E. C. $(1969 b)$. The $\gamma$ particle, satellite ribosome package, and spheroidal mitochondrion in the zoospore of Blastocladiella emersonii. Phytopathology 59, 1060.

Cantino, E. C. \& Goldstein, A. (1967). Citrate-induced citrate production and light-induced growth of Blastocladiella emersonii. J. gen. Microbiol. 46, 347.

CANTino, E. C. \& Horenstein, E. A. (1956). Gamma and the cytoplasmic control of differentiation in Blastocladiella. Mycologia 48, 443 .

Cantino, E. C. \& HyatT, M. T. (I953a). Phenotypic 'sex' determination in the life history of a new species of Blastocladiella, B. emersonii. Antonie van Leeuwenhoek, J. Microbiol. Serol. 19, 25.

Cantino, E. C. \& Hyatr, M. T. (1953b). Carotenoids and oxidative enzymes in the aquatic Phycomycetes Blastocladiella and Rhizophlyctis. Am. J. Bot. 40, 688.

Cantino, E. C. \& Lovetr, J. S. (I964). Non-filamentous aquatic fungi : model systems for biochemical studies of morphological differentiation. Adv. Morphogen. 3, 33 .

CANTINo, E. C. \& MACK, J. P. (1969). Form and function in the zoospore of Blastocladiella emersonii. I. The $\gamma$ particle and the satellite ribosome package. Nova Hedwigia (in the Press).

Cantino, E. C., Suberkropp, K. F. \& Truesdell, L. C. (1969). Form and function in the zoospore of Blastocladiella emersonii. II. Spheroidal mitochondria and respiration. Nova Hedwigia (in the Press).

Cantino, E. C., Truesdell, L. C. \& Shaw, D. S. (1968). Life history of the motile spore of Blastocladiella emersonii: a study in cell differentiation. J. Elisha Mitchell scient. Soc. 84, I 25.

Cantino, E. C., Lovett, J. S., Leak, L. V. \& Lythgoe, J. (1963). The single mitochondrion, fine structure and germination of the spore of Blastocladiella emersonii. J. gen. Microbiol. $3 \mathbf{r}, 393$.

Chambers, T. C., Markus, K. \& Willoughby, L. G. (1967). The fine structure of the mature zoosporangium of Nowakowskiella profusa. J. gen. Microbiol. 46, 135.

DeERING, R. A. (I968). Radiation studies of Blastocladiella emersonii. Radiat. Res. 34, 87.

DE LONG, S. K. (1965). Studies on the genetic control of resistant sporangium formation in Allomyces. Am. J. Bot. 52, 999.

DomnAs, A. (1968). Refractory response of Blastocladiella emersonii to bicarbonate. Mycologia 60 , 698.

EMERSON, R. (1950). Current trends of experimental research on the aquatic Phycomycetes. $A$. Rev Microbiol. 4, 169. 
EMERSON, R. \& WiLSON, C.M. (1954). Interspecific hybrids and the cytogenetics and cytotaxonomy of Euallomyces. Mycologia 46, 393.

Foley, J. M. (1958). The occurrence, characteristics and genetic behavior of albino gametophytes in Allomyces. Am. J. Bot. 45, 639.

Fuller, M. S. (1966). Structure of the uniflagellate zoospores of aquatic Phycomycetes. Proc. I8th Symp. Colston Res. Soc. 18, 67.

Fuller, M. S. \& Calmoun, S. A. (1968). Microtubule-kinetosome relationships in the motile cells of the Blastocladiales. Z. Zellforsch. mikrosk. Anat. 87, 526.

FULLER, M. S. \& REICHLE, R. E. (I968). The fine structure of Monoblepharella sp. zoospores. Can. J. Bot. 46, 279.

Horenstein, E. A. \& Cantino, E. C. (196I). Morphogenesis in, and the effect of light on, Blastocladiella britannica sp. nov. Trans. Br. mycol. Soc. 44, I85.

LESSIE, P. E. \& LOVETT, J. S. (1968). Ultrastructural changes during sporangium formation and zoospore differentiation in Blastocladiella emersonii. Am. J. Bot. 55, 220.

LOVETT, J. S. (1963). Chemical and physical characterization of 'nuclear caps' isolated from Blastocladiella zoospores. J. Bact. 5, I235.

LOVETT, J.S. (I968). Reactivation of ribonucleic acid and protein synthesis during germination of Blastocladiella zoospores and the role of the ribosomal nuclear cap. J. Bact. 96, 962.

MULLINS, J. T. \& RAPER, J. R. (1965). Heterothallism in biflagellate aquatic fungi: preliminary genetic analysis. Science, N.Y. 150, II 74 .

MURPhy, Sister, M. N. \& LOVETT, J. S. (1966). RNA and protein synthesis during zoospore differentiation in synchronized cultures of Blastocladiella. Devl. Biol. 14, 68.

ReICHLE, R. E. \& FulleR, M. S. (1967). The fine structure of Blastocladiella emersonii zoospores. Am. J. Bot. 54, 8 I.

Roth, L. E. (1967). Electron microscopy of mitosis in amoebae. III. Cold and urea treatments: a basis for tests of direct effects of mitotic inhibitors on microtubule formation. J. Cell Biol. 34, 47.

SANSOME, E. (1965). Meiosis in diploid and polyploid sex organs of Phytophthora and Achlya. Cytologia 30, I03.

SChramm, M., EISENKRAFT, B. \& BARKAI, E. (1967). Cold-induced leakage of amylase from the zymogen granule and sealing of its membrane by specific lipids. Biochim. biophys. Acta 135, 44.

Soll, D. R., Bromberg, R. \& SonNeborn, D. R. (1969). Zoospore germination in the water mold, Blastocladelia emersonii. I. Measurement of germination and sequence of subcellular morphological changes. Devl Biol. 20, I83.

Stumm, C. (1958). Die Analyse von Genmutanten mit geänderten Fortpflanzungseigenschaften bei Allomyces arbuscula Butl. Z. VererbungLehre 89, $52 \mathrm{I}$.

TiLney, L. G. \& PorTer, K. R. (1967). Studies on microtubules in Heliozoa. II. The effect of low temperature on these structures in the formation and maintenance of axopodia. J. Cell Biol. 34, 327.

\section{EXPLANATION OF PLATES}

Plate I

Fig. I and 2. Zoospores harvested from PYG agar cultures of wild type var. I and strain 9, respectively; chilled $2 \mathrm{hr}$ before permanganate fixation. Arrows point to breaks in nuclear cap. $\times 13,300$ and $x$ 13,600 .

Plate 2

Fig. 3 and 4. Zoospores harvested from PYG agar cultures of strain 9; chilled $2 \mathrm{hr}$ before permanganate fixation. Solid arrows point to breaks in nuclear cap; for dotted arrow, see text. $\times 1400$ and $\times 14,300$.

\section{Plate 3}

Fig. 5 and 6. Zoospore harvested from PYG agar culture, and a sporangium undergoing sporogenesis harvested from PYG-PC spinner flask cultures, respectively, of strain 9; the spore was chilled $2 \mathrm{hr}$ before permanganate fixation. Arrows point to breaks in nuclear membrane. $\times 16,800$ and $\times 17,100$. 


\section{Plate 4}

Fig. 7. Zoospore harvested from PYG agar culture of wild type var. I; chilled $2 \mathrm{hr}$ before permanganate fixation. Arrow points to anchoring loop of mitochondrion; see text. $\times 34,600$.

Fig. 8. Zoospore harvested from PYG-PC spinner flask culture of albino mutant strain 9; unchilled, fixed with glutaraldehyde-osmic acid, and stained with uranyl acetate and lead citrate. $\times 37,900$.

\section{Plate 5}

Fig. 9. Zoospore harvested from PYG agar culture of strain 9; chilled $2 \mathrm{hr}$ before permanganate fixation. Arrow points to connection of nuclear cap and nuclear membranes. $\times 31,000$.

\section{Plate 6}

Fig. Io and Fig. II. Zoospores harvested from PYG agar cultures of wild type var. I and strain 9, respectively; chilled $2 \mathrm{hr}$ before permanganate fixation. $\times 31,500$ and $\times 31,600$. 
Journal of General Microbiology, Vol. 59, No. 3

Plate I
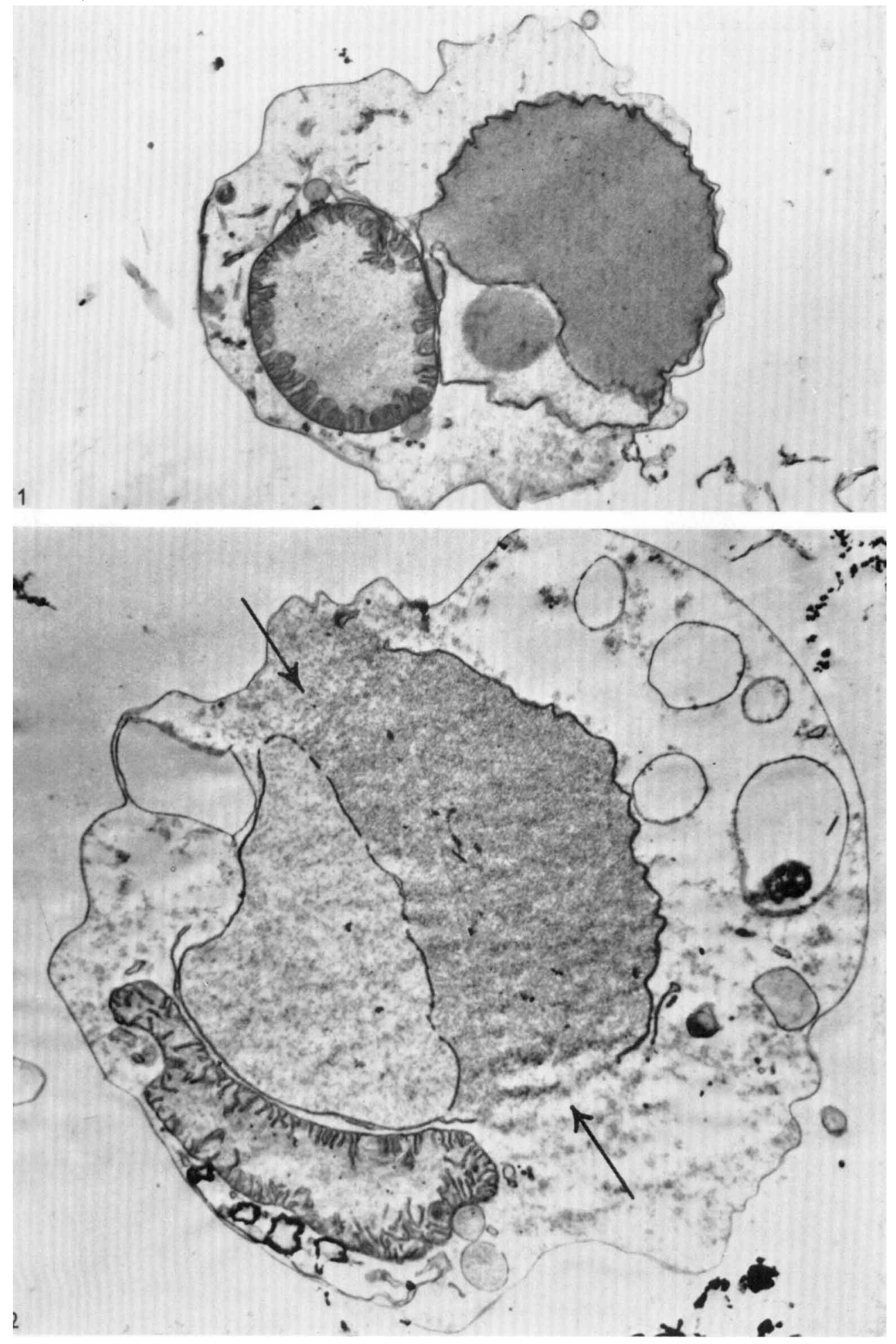

D. S. SHAW AND E. C. CANTINO

(Facing p. 382) 
Journal of General Microbiology, Vol. 59, No. 3

Plate 2

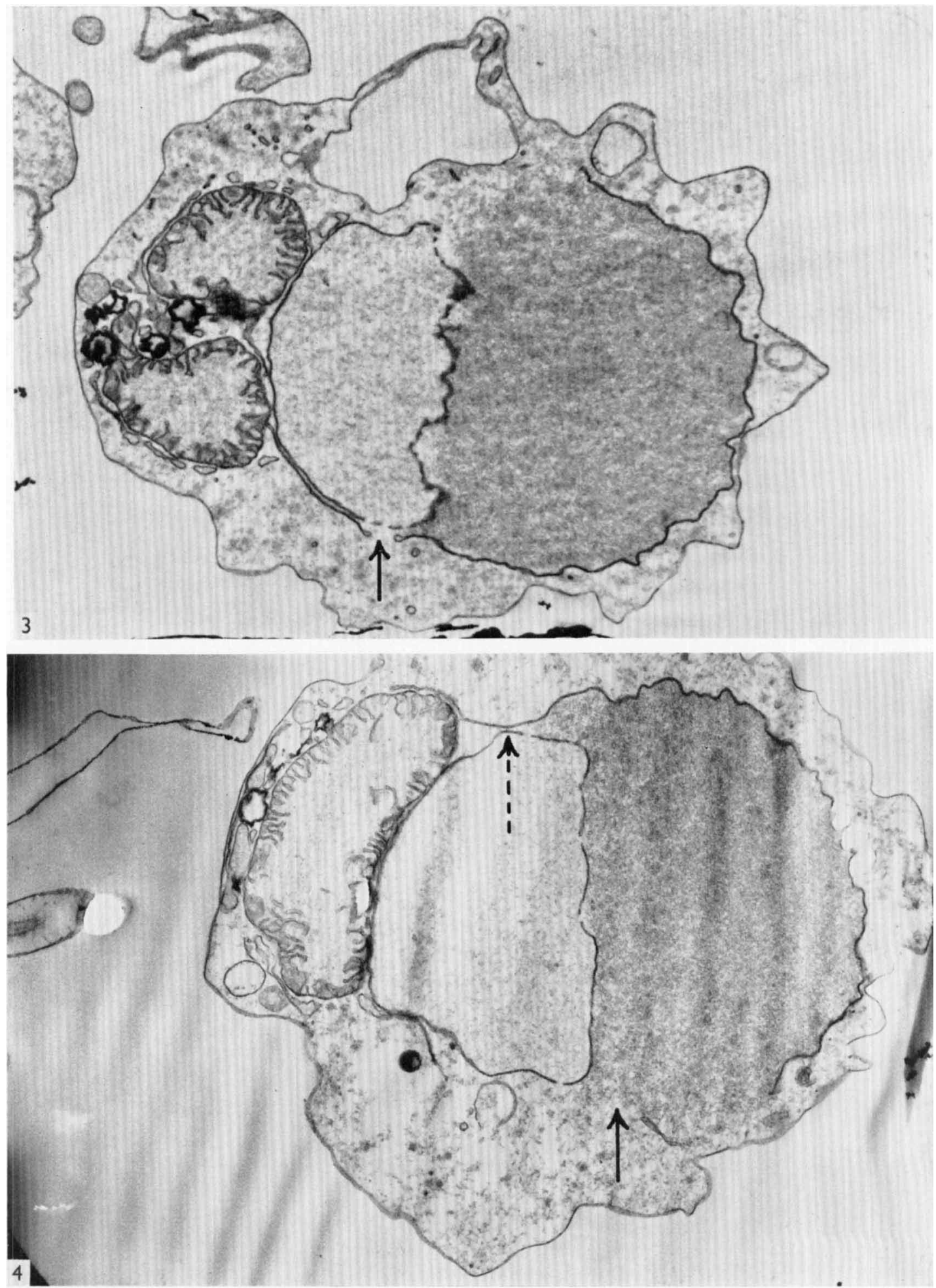

D. S. SHAW AND E. C. CANTINO 
Journal of General Microbiology, Vol. 59, No. 3

Plate 3
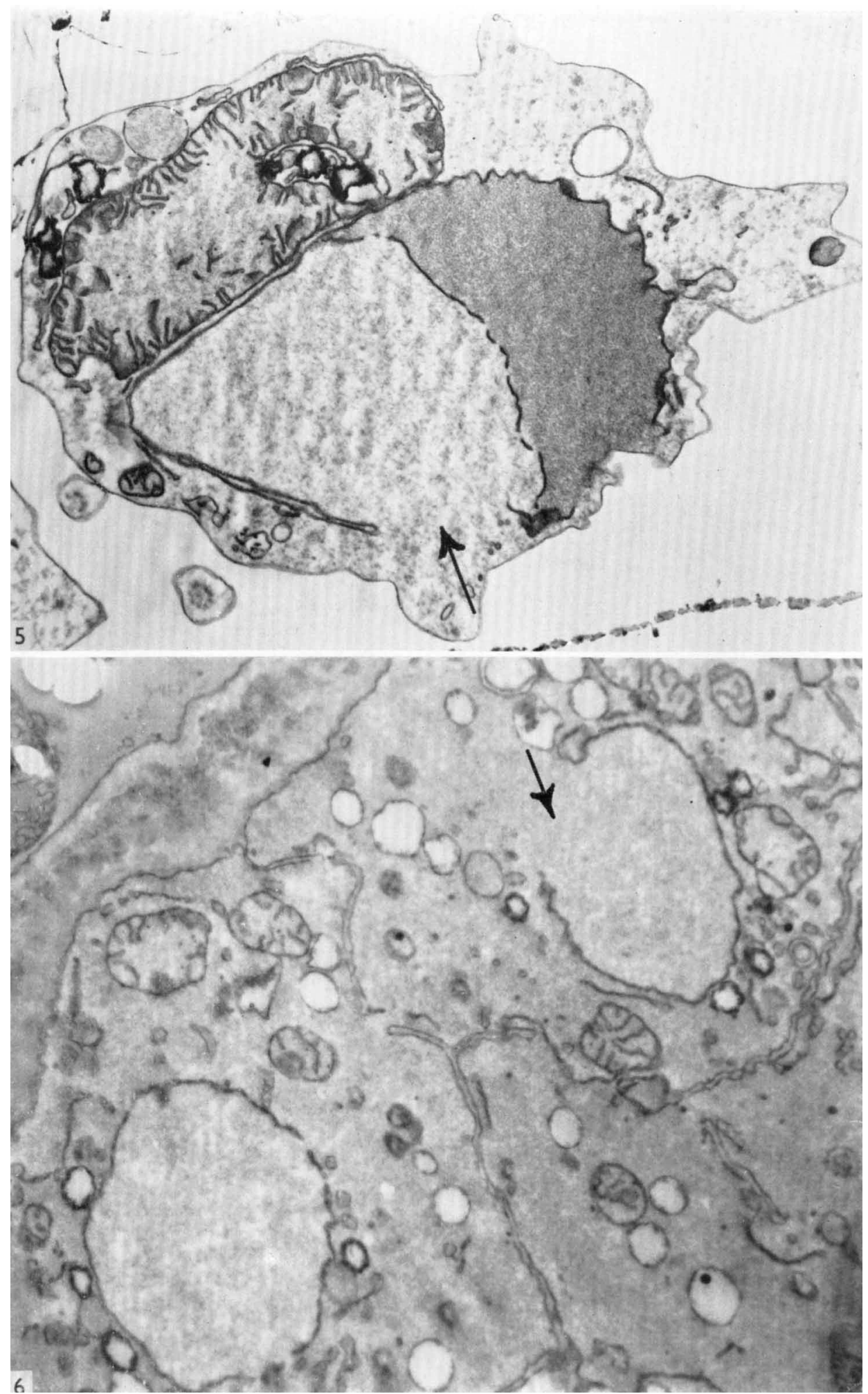

D. S. SHAW AND E. C. CANTINO 
Journal of General Microbiology, Vol. 59, No. 3

Plate 4
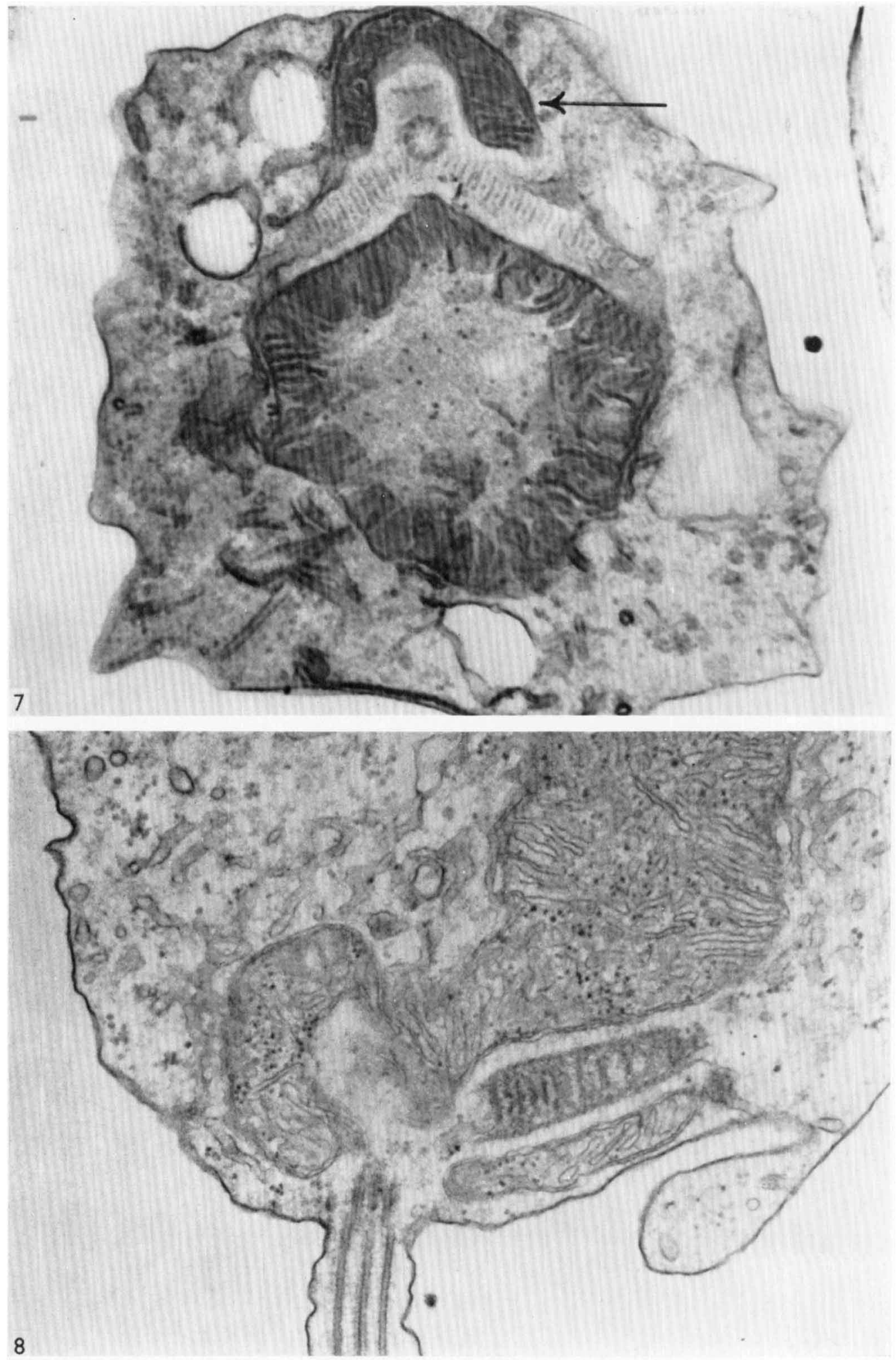

D. S. SHAW AND E. C. CANTINO 


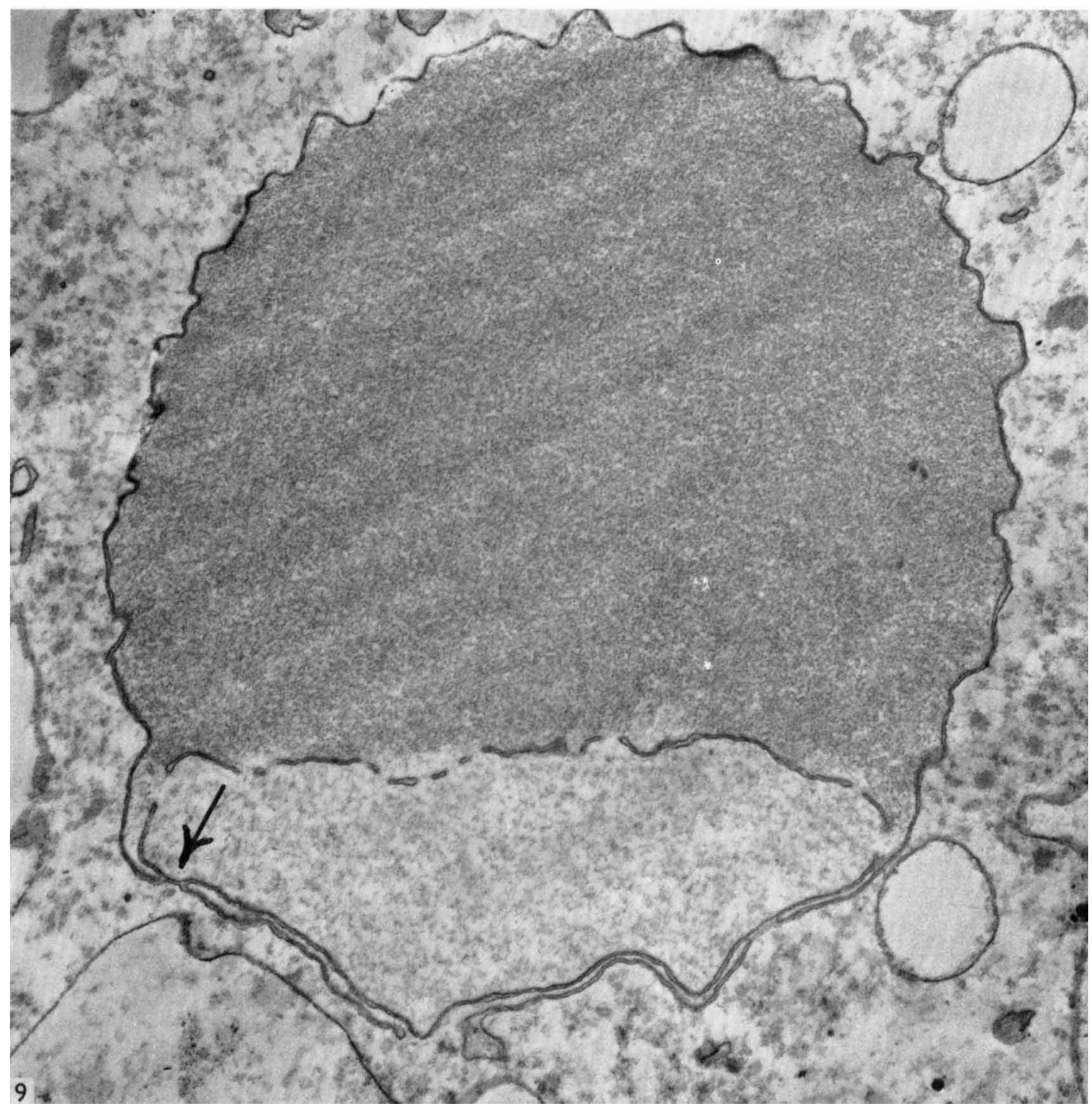

D. S. SHAW AND E. C. CANTINO 
Journal of General Microbiology, Vol. 59, No. 3

Plate 6

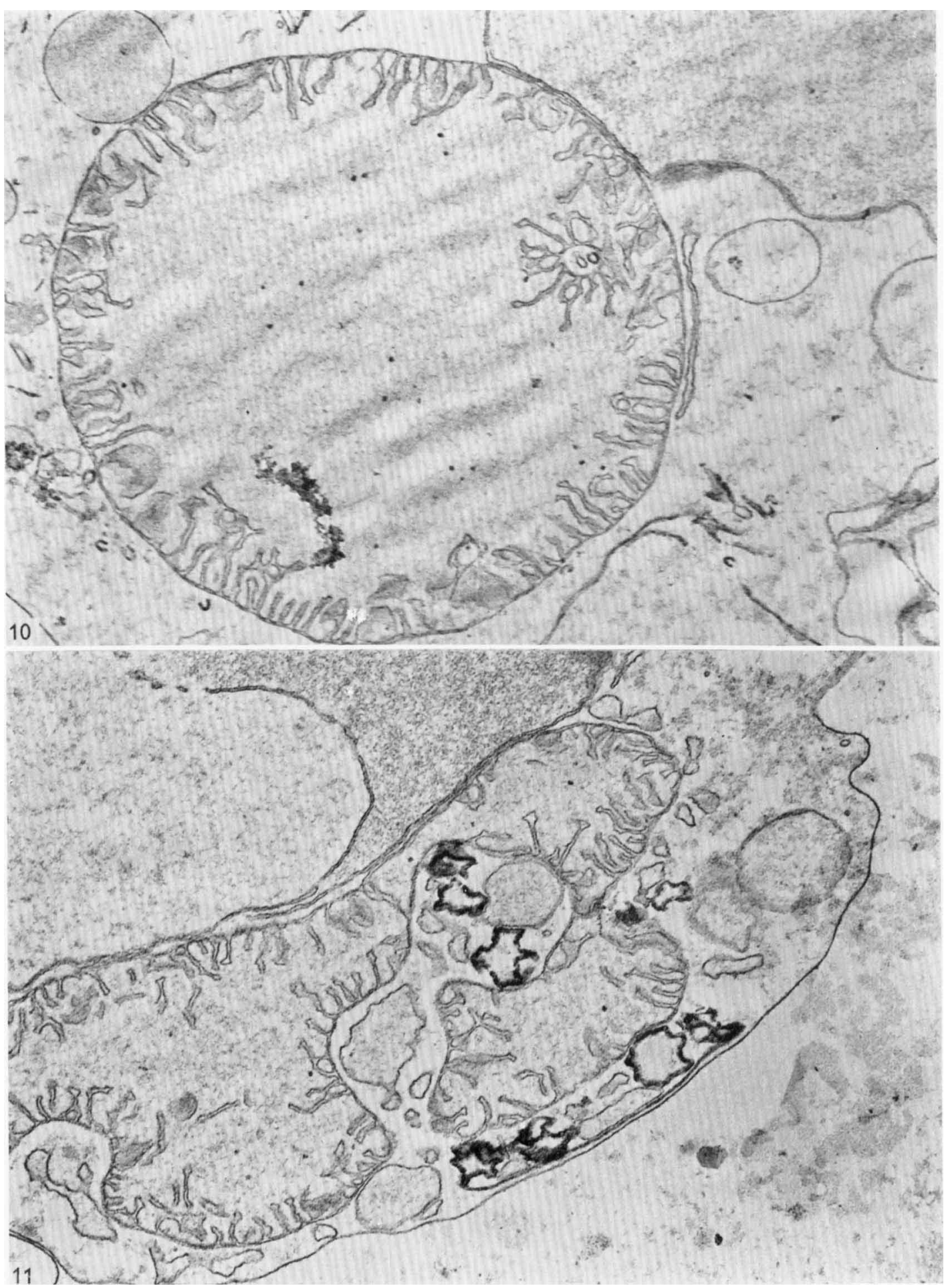

D. S. SHAW AND E. C. CANTINO 